\title{
Compositional modeling and simulation of dimethyl ether (DME)- enhanced waterflood to investigate oil mobility improvement
}

\author{
Jinhyung $\mathrm{Cho}^{1} \cdot$ Tae Hong Kim ${ }^{1} \cdot$ Kun Sang Lee ${ }^{1}$
}

Received: 26 July 2017 / Published online: 6 January 2018

(c) The Author(s) 2018. This article is an open access publication

\begin{abstract}
Dimethyl ether (DME) is a widely used industrial compound, and Shell developed a chemical EOR technique called DMEenhanced waterflood (DEW). DME is applied as a miscible solvent for EOR application to enhance the performance of conventional waterflood. When DME is injected into the reservoir and contacts the oil, the first-contact miscibility process occurs, which leads to oil swelling and viscosity reduction. The reduction in oil density and viscosity improves oil mobility and reduces residual oil saturation, enhancing oil production. A numerical study based on compositional simulation has been developed to describe the phase behavior in the DEW model. An accurate compositional model is imperative because DME has a unique advantage of solubility in both oil and water. For DEW, oil recovery increased by $34 \%$ and $12 \%$ compared to conventional waterflood and $\mathrm{CO}_{2}$ flood, respectively. Compositional modeling and simulation of the DEW process indicated the unique solubility effect of DME on EOR performance.
\end{abstract}

Keywords Dimethyl ether (DME) · DME-enhanced waterflood (DEW) - Solubility · Oil mobility

\section{Introduction}

The performance of hydrocarbon gas and $\mathrm{CO}_{2}$ injection for EOR has been actively studied on both field and laboratory scales for decades (Fassihi and Gillham 1993; Talbi et al. 2008; Hu et al. 2015). Moreover, the application of solvents, such as isopropyl and methyl alcohols, for EOR has been studied (Gatlin and Slobod 1960; Taber et al. 1961). Recently, dimethyl ether (DME) was investigated as a potential solvent for EOR.

DME, a well-known industrial chemical used as a fuel additive and aerosol propellant, has recently been used as a replacement for transport, cooking, and heating fuels (DME Handbook 2007; Chernetsky et al. 2015). In recent years, DME has been considered as a solvent for EOR. In particular, Shell has studied and developed this process (Chernetsky et al. 2015; Groot et al. 2016; Parsons et al.

Edited by Yan-Hua Sun

Kun Sang Lee

kunslee@hanyang.ac.kr

1 Department of Earth Resources and Environmental Engineering, Hanyang University, 222 Wangsimni-ro, Seongdong-gu, Seoul 04763, Republic of Korea
2016). DME is often compared to LPG due to their similar physical properties; however, the solubility of DME in water is almost 1000-fold greater than that of propane (Parsons et al. 2016).

However, only a few experimental studies have examined the effect of DME on the EOR process, and a compositional simulation model has not yet been developed. DME is applied to conventional waterflood because of its high solubility in the oleic phase and its dissolution in water. DME is a first-contact miscible solvent with reservoir oil and is also partially soluble in water because of its polarity, $\mu=1.3 \mathrm{D}$, where $\mu$ is the dipole moment and $\mathrm{D}$ is the Debye unit where $1 \mathrm{D}$ is $10^{-18}$ electrostatic units of charge times centimeters (Nelson et al. 1967). After conventional waterflood, residual oil remains in the pores due to the poor mobility of oil. Injected DME becomes miscible with residual oil, which causes oil viscosity reduction and swelling, leading to improved mobility. DME remaining in the oil phase after flooding can be extracted by chase water, which provides an economic benefit from re-injection of chase water. Back-recovered DME in chase water not only allows re-injection, but it acts as a carrier to improve oil mobility near the producer that was not affected by the initial DME injection. DME-enhanced waterflood (DEW), indicated in Fig. 1, has a totally 

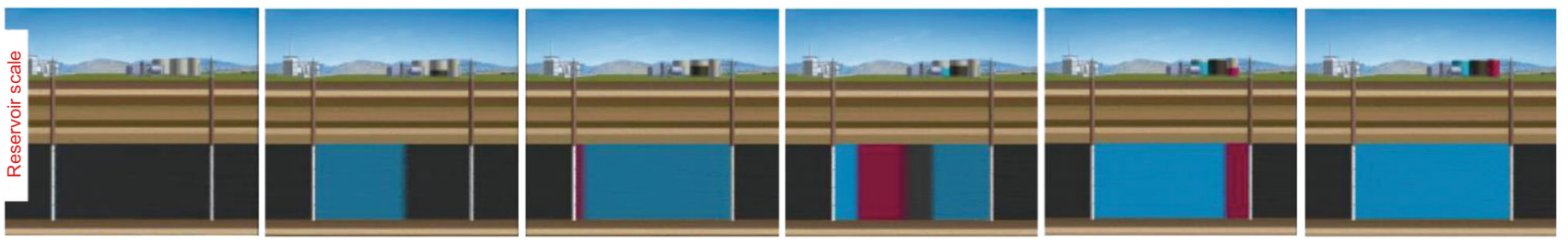

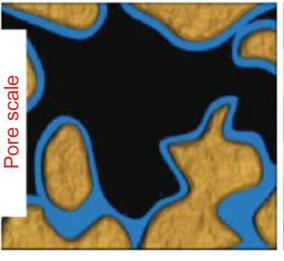

Virgin reservoi

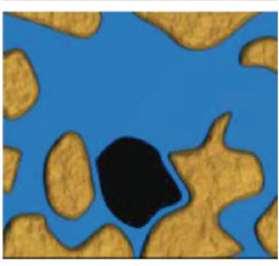

Water flood

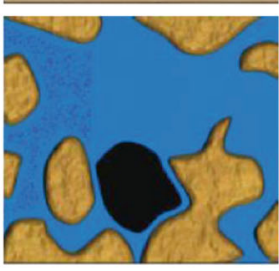

Injection of DME/water

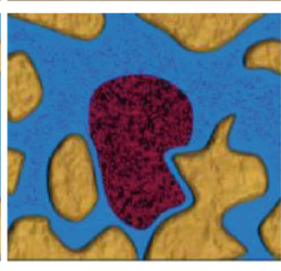

Oil swells/viscosity drops
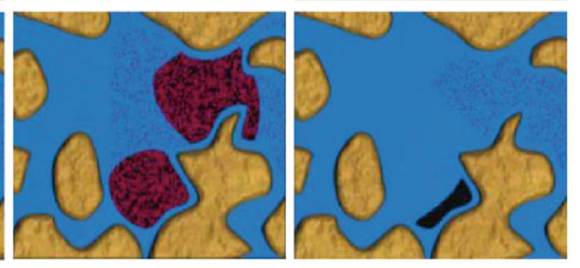

Mobilization of oil/DME mixture Chase water/recovery of DME

Life cycle of a reservoir (Time)

Fig. 1 Visualization of the DEW process on reservoir and pore scales (Chernetsky et al. 2015)

different transport mechanism compared to water and other gas flooding due to the unique characteristics of DME. For an accurate description of the DEW process to forecast recovery performance, a compositional simulation model was developed. Based on the simulation study, improvement in displacement efficiency by DEW was estimated in terms of oil viscosity reduction and the swelling effect. Moreover, analysis was performed for the effect of the water solubility of DME on the transport mechanism.

\section{Numerical simulation}

\subsection{Fluid modeling}

Weyburn reservoir fluid data were used for the compositional simulation. The fluid properties, calculated through a regression process to match the experimental data, are compared with actual fluid data in Table 1 (Srivastava et al. 2000). The Peng-Robinson (PR) equation of state (EOS) (Peng and Robinson 1976; Robinson and Peng 1978), implemented in Winprop software, was applied to calculate the fugacity of components in the oil and gas

Table 1 Comparison of properties of the fluid model and Weyburn data

\begin{tabular}{lll}
\hline Parameters & Fluid model & Weyburn \\
\hline Saturation pressure, psi & 694 & 713 \\
Oil density, $\mathrm{lb} / \mathrm{ft}^{3}$ & 50.3 & 50.3 \\
Oil viscosity at $p_{\text {sat }}, \mathrm{cP}$ & 1.76 & 1.76 \\
Formation volume factor, $\mathrm{ft}^{3} / \mathrm{ft}^{3}$ & 1.11 & 1.12 \\
Oil gravity, API & 35 & 31 \\
\hline
\end{tabular}

phases and to determine DME solubility and phase behavior of the fluid model with the reservoir oil and injected fluid. The PR EOS is given by

$p=\frac{R T}{v-b}-\frac{a}{v(v+b)+b(v-b)}$,

or in terms of $Z$ factor:

$$
\begin{aligned}
& Z^{3}-(1-B) Z^{2}+\left(A-3 B^{2}-2 B\right) Z-\left(A B-B^{2}-B^{3}\right) \\
& \quad=0
\end{aligned}
$$

and

$Z_{\mathrm{c}}=0.3074$.

The EOS constants for pure components are given by

$$
\begin{aligned}
& A=a \frac{p}{(R T)^{2}}, \\
& B=b \frac{p}{R T}, \\
& a=\Omega_{a}^{\mathrm{o}} \frac{R^{2} T_{\mathrm{c}}^{2}}{p_{\mathrm{c}}} \alpha, \\
& b=\Omega_{b}^{\mathrm{o}} \frac{R T_{\mathrm{c}}}{p_{\mathrm{c}}}, \\
& \alpha=\left[1+m\left(1-\sqrt{T_{\mathrm{r}}}\right)\right]^{2},
\end{aligned}
$$

where $\quad \Omega_{a}^{\mathrm{o}}=0.45724, \quad \Omega_{b}^{\mathrm{o}}=0.07780, \quad$ and $m=0.37464+1.54226 \omega-0.26992 \omega^{2}$.

Robinson and Peng (1978) proposed a modified $m$ for heavier components $(\omega>0.49)$ as follows:

$m=0.3796+1.485 \omega-0.1644 \omega^{2}+0.01667 \omega^{3}$.

Fugacity expressions are given by 


$$
\begin{aligned}
\ln \phi_{i}= & Z-1-\ln (Z-B) \\
& -\frac{A}{2 \sqrt{2} B}\left(\frac{B_{i}}{B}-\frac{2}{A} \sum_{j=1}^{N} y_{i} A_{i j}\right) \ln \left[\frac{Z+(1+\sqrt{2}) B}{Z-(1-\sqrt{2}) B}\right],
\end{aligned}
$$

where mixing rules are used for the multicomponent fugacity expression as follows:

$A=\sum_{i=1}^{N} \sum_{j=1}^{N} y_{i} y_{j} A_{i j}$

$B=\sum_{i=1}^{N} y_{i} B_{i}$,

$A_{i j}=\left(1-k_{i j}\right) \sqrt{A_{i} A_{j}}$,

where $k_{i j}$ are binary interaction parameters.

All PR EOS components of DME were gathered from a literature reference (Ganjdanesh et al. 2016). It was assumed that the gaseous, oleic, and aqueous phases were in thermodynamic equilibrium. To calculate the fugacity of DME in the aqueous phase for DME solubility in water, Henry's law was used (Li and Nghiem 1986):

$f_{i \mathrm{w}}=y_{i \mathrm{w}} H_{i}, \quad i=1,2,3, \ldots, n_{\mathrm{c}}$,

where $H_{i}$ is Henry's constant of component $i$; and $y_{i \mathrm{w}}$ is the mole fraction of component $i$ in the aqueous phase. The following equation was then used to calculate Henry's constants at other pressures:

$\ln H_{i}=\ln H_{i}^{*}+\frac{\overline{v_{i}}\left(p-p^{*}\right)}{R T}$,

where $H_{i}^{*}$ is Henry's constant for component $i$ at reference pressure $p^{*}$ and temperature $T$; and $\overline{v_{i}}$ is the partial molar volume of component $i$. These values were obtained from a literature reference (Sander 2015). All fugacity values gained from PR EOS and Henry's law determined not only phase behavior, but also DME solubility in oil and water phases.

The general equation for calculating the interfacial tension (IFT) consists of the molar density of liquid $\left(\rho_{\mathrm{L}}\right)$ and vapor $\left(\rho_{\mathrm{V}}\right)$, and parachor $\left(p_{\mathrm{ar}}\right)$ (Reid et al. 1977):

$\sigma=p_{\mathrm{ar}}\left(\rho_{\mathrm{L}}-\rho_{\mathrm{V}}\right)$.

For multicomponent systems:

$\sigma=\sum_{i=1}^{n_{\mathrm{c}}} p_{\mathrm{ar}_{i}}\left(x_{i} \rho_{\mathrm{L}}-y_{i} \rho_{\mathrm{V}}\right)$,

where

$p_{\mathrm{ar}_{i}}=\xi C N_{i}$,

$\xi=\left\{\begin{array}{l}40(C N \leq 12) \\ 40.3(C N>12)\end{array}\right\}, C N_{i}=M W_{i} / 14$, where $M W_{i}$ is the molecular weight of component $i$.

The Pedersen viscosity correlation of a mixture is calculated according to the following formula (Pedersen and Fredenslund 1987):

$\frac{\mu_{\text {mix }}(P, T)}{\mu_{\mathrm{o}}\left(P_{\mathrm{o}}, T_{\mathrm{o}}\right)}=\left(\frac{T_{\mathrm{c}, \text { mix }}}{T_{\mathrm{c}, \mathrm{o}}}\right)^{-1 / 6}\left(\frac{P_{\mathrm{c}, \text { mix }}}{P_{\mathrm{c}, \mathrm{o}}}\right)^{2 / 3}\left(\frac{M W_{\text {mix }}}{M W_{\mathrm{o}}}\right)^{1 / 2}\left(\frac{\alpha_{\text {mix }}}{\alpha_{\mathrm{o}}}\right)$,

where $\mu$ is viscosity; $T_{\mathrm{c}}$ is the critical temperature; $P_{\mathrm{c}}$ is the critical pressure; $M W$ is the molecular weight; $\alpha$ is the rotational coupling coefficient; and the subscripts "mix" and "o" refer to the mixture and reference substance.

The critical pressure and temperature of the mixture are calculated by mixing rules with PR EOS, and the molecular weight of the mixture is gained from the following equation:

$M W_{\text {mix }}=b_{1}\left(M W_{\mathrm{w}}^{b_{2}}-M W_{\mathrm{n}}^{b_{2}}\right)+M W_{\mathrm{n}}$,

$\alpha=1+b_{3} \rho_{\mathrm{r}}^{b_{4}} M W^{b_{5}}$,

where $M W_{\mathrm{w}}$ is the weight-average molecular weight; $M W_{\mathrm{n}}$ is the mole-average molecular weight; and $\rho_{\mathrm{r}}$ is the reduced density of the reference substance. Coefficients $b_{i}$ were matched to experimental data of viscosity (Table 1).

Oil composition and properties of each component are shown in Table 2, and the binary interaction coefficients are shown in Table 3. Also, PVT properties of the Weyburn fluid and $\mathrm{CO}_{2}$ mixtures at $145^{\circ} \mathrm{F}$ are present in Table 4.

\subsection{Reservoir modeling}

The GEM compositional simulator, developed by Computer Modeling Group (CMG), was used for numerical simulation. The reservoir model size was $310 \mathrm{ft} \times 10 \mathrm{ft} \times$ $10 \mathrm{ft}$, and it was a homogeneous 1-D model to focus on the transport phenomenon during DEW. Therefore, oil recovery was governed only by the effect of mobility improvement by DME injection and solubility in oil and water. The reservoir had mixed-wet conditions, and the relative permeability curve was obtained from a literature reference (Fig. 2, Fazelipour 2011). Conventional water (Model 1) and $\mathrm{CO}_{2}$ (Model 2) flood models were baseline cases. After the reservoir was waterflooded for three years, DME was injected for one year and then freshwater was chased. The model had two scenarios that either considered water solubility (Model 3) or did not consider water solubility (Model 4). For comparison, LPG, which is the first-contact miscible with hydrocarbon, was injected instead of DME flood (Model 5). Although the molecular weight of DME is similar to that of LPG, it has advantages of re-injection and low cost with high efficiency due to chase water solubility. 
Table 2 Oil composition and properties of each component
Table 3 Binary interaction coefficients

\begin{tabular}{llrrll}
\hline Component & Mole fraction & $P_{\mathrm{c}}, \mathrm{psi}$ & \multicolumn{1}{l}{$T_{\mathrm{c}},{ }^{\circ} \mathrm{F}$} & Acentric factor & Molecular weight \\
\hline $\mathrm{N}_{2}$ & 0.0207 & 492 & -232.69 & 0.04 & 28.01 \\
$\mathrm{CO}_{2}$ & 0.0074 & 1070 & 87.89 & 0.225 & 44.01 \\
$\mathrm{H}_{2} \mathrm{~S}$ & 0.0012 & 1297 & 212.09 & 0.1 & 34.08 \\
Methane & 0.0749 & 667 & -116.59 & 0.008 & 16.04 \\
Ethane & 0.0422 & 709 & 90.05 & 0.098 & 30.07 \\
Propane & 0.0785 & 616 & 205.97 & 0.152 & 44.10 \\
DME & 0.0001 & 790 & 260.84 & 0.2 & 46.07 \\
Butane & 0.0655 & 540 & 290.1 & 0.1845 & 58.12 \\
Pentane & 0.0459 & 490 & 377.3 & 0.239 & 72.15 \\
$\mathrm{C}_{6-9}$ & 0.2155 & 438 & 541.79 & 0.331 & 102.5 \\
$\mathrm{C}_{10-17}$ & 0.2202 & 293 & 786.46 & 0.584 & 184 \\
$\mathrm{C}_{18-27}$ & 0.1027 & 193 & 995.5 & 0.893 & 306.2 \\
$\mathrm{C}_{28+}$ & 0.1252 & 168 & 1188.3 & 1.1 & 565.61 \\
\hline
\end{tabular}

\begin{tabular}{lllllllllllllll}
\hline & $\mathrm{N}_{2}$ & $\mathrm{CO}_{2}$ & $\mathrm{H}_{2} \mathrm{~S}$ & $\mathrm{C}_{1}$ & $\mathrm{C}_{2}$ & $\mathrm{C}_{3}$ & $\mathrm{DME}$ & $\mathrm{C}_{4}$ & $\mathrm{C}_{5}$ & $\mathrm{C}_{6-9}$ & $\mathrm{C}_{10-17}$ & $\mathrm{C}_{18-27}$ & $\mathrm{C}_{28+}$ \\
\hline $\mathrm{N}_{2}$ & 0.00 & - & - & - & - & - & - & - & - & - & - & - & - \\
$\mathrm{CO}_{2}$ & 0.00 & 0.00 & - & - & - & - & - & - & - & - & - & - & - \\
$\mathrm{H}_{2} \mathrm{~S}$ & 0.13 & 0.14 & 0.00 & - & - & - & - & - & - & - & - & - & - \\
$\mathrm{C}_{1}$ & 0.25 & 0.11 & 0.07 & 0.00 & - & - & - & - & - & - & - & - & - \\
$\mathrm{C}_{2}$ & 0.01 & 0.13 & 0.09 & 0.00 & 0.00 & - & - & - & - & - & - & - & - \\
$\mathrm{C}_{3}$ & 0.09 & 0.13 & 0.08 & 0.01 & 0.00 & 0.00 & - & - & - & - & - & - & - \\
$\mathrm{DME}_{2}$ & 0.10 & 0.00 & 0.00 & 0.29 & 0.25 & 0.25 & 0.00 & - & - & - & - & - & - \\
$\mathrm{C}_{4}$ & 0.10 & 0.12 & 0.08 & 0.02 & 0.01 & 0.00 & 0.25 & 0.00 & - & - & - & - & - \\
$\mathrm{C}_{5}$ & 0.10 & 0.12 & 0.07 & 0.02 & 0.01 & 0.00 & 0.25 & 0.00 & 0.00 & - & - & - & - \\
$\mathrm{C}_{6-9}$ & 0.11 & 0.12 & 0.05 & 0.03 & 0.02 & 0.01 & 0.20 & 0.00 & 0.00 & 0.00 & - & - & - \\
$\mathrm{C}_{10-17}$ & 0.11 & 0.12 & 0.05 & 0.06 & 0.04 & 0.02 & 0.08 & 0.02 & 0.01 & 0.01 & 0.00 & - & - \\
$\mathrm{C}_{18-27}$ & 0.11 & 0.12 & 0.05 & 0.09 & 0.06 & 0.05 & 0.08 & 0.03 & 0.03 & 0.02 & 0.00 & 0.00 & - \\
$\mathrm{C}_{28+}$ & 0.11 & 0.12 & 0.05 & 0.12 & 0.09 & 0.07 & 0.08 & 0.05 & 0.05 & 0.03 & 0.01 & 0.00 & 0.00 \\
\hline
\end{tabular}

Table 4 PVT properties of Weyburn reservoir fluid and $\mathrm{CO}_{2}$ mixture at $145^{\circ} \mathrm{F}$

\begin{tabular}{llccll}
\hline $\mathrm{CO}_{2}$ concentration, mol $\%$ & $P_{\text {sat }}, \mathrm{psi}$ & GOR & Gas solubility & Viscosity $\mu, \mathrm{cP}$ & Swelling factor \\
\hline 0.74 & 713 & 32 & 0 & 1.76 & 1.09 \\
22.9 & 1044 & 80 & 48 & 1.32 & 1.21 \\
36.4 & 1334 & 119 & 87 & 1.03 & 1.30 \\
43.4 & 1508 & 154 & 122 & 0.87 & 1.40 \\
51.4 & 1725.5 & 204 & 172 & 0.70 & 1.48 \\
59.9 & 2088 & 277 & 245 & 0.53 & 1.64 \\
66.0 & 2465 & 317 & 285 & 0.45 & 1.73 \\
\hline
\end{tabular}

The initial reservoir conditions and operating conditions are listed in Table 5 (Fazelipour 2011).

\section{Results and discussion}

\subsection{Displacement efficiency}

When $\mathrm{CO}_{2}$ is injected into a reservoir, it causes oil viscosity reduction and oil swelling to improve displacement efficiency. However, for stronger effects, the reservoir pressure should be higher than the minimum miscibility 

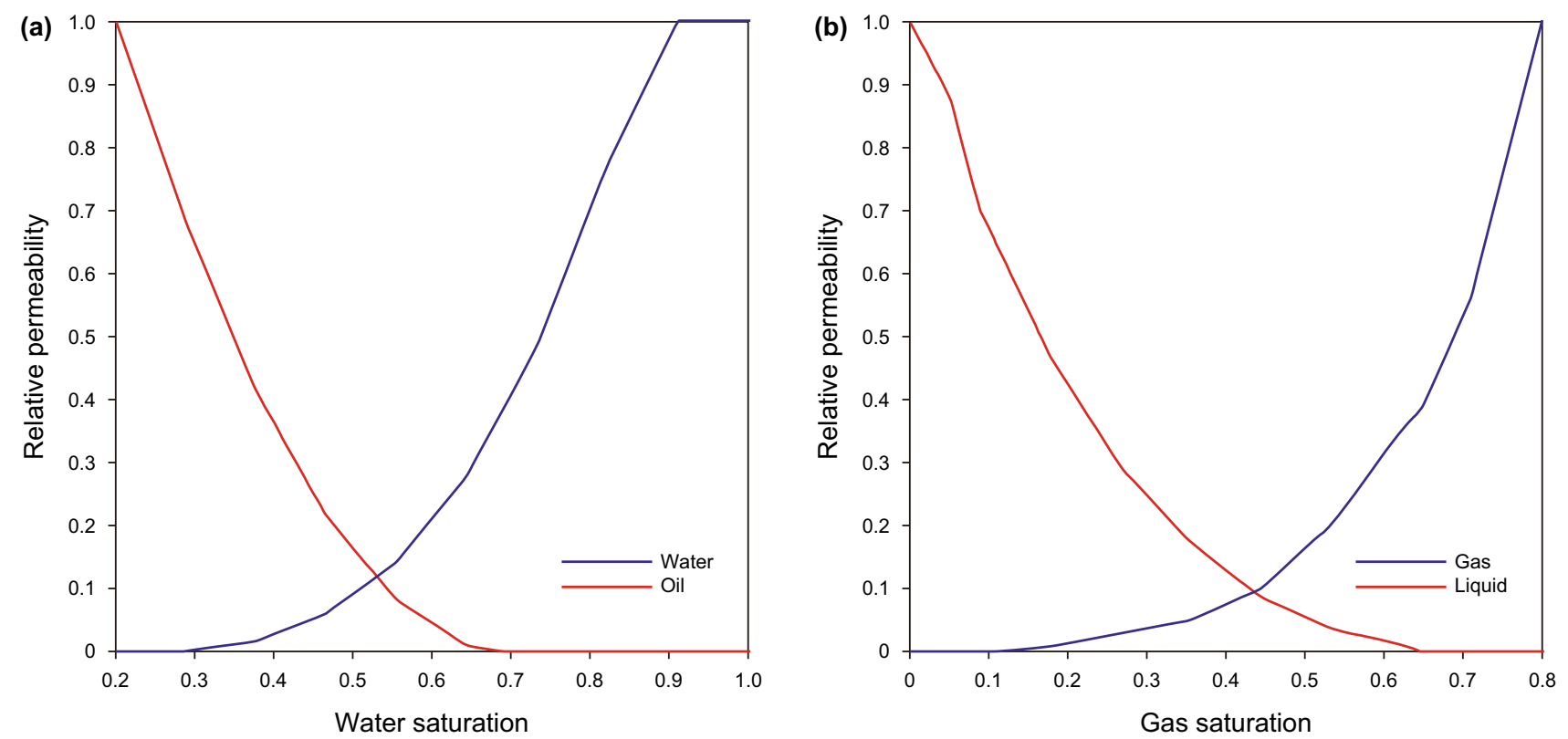

Fig. 2 Relative permeability curves for water-oil (a) and liquid-gas (b) systems

Table 5 Reservoir initial and operating conditions

\begin{tabular}{ll}
\hline Properties & Values \\
\hline Depth, ft & 4000 \\
Pressure, psi & 2000 \\
Temperature, ${ }^{\circ} \mathrm{F}$ & 145 \\
Permeability, mD & 20 \\
Porosity, \% & 30 \\
Initial oil saturation $S_{\mathrm{o}}$ & 0.8 \\
Connate water saturation $S_{\mathrm{w}}$ & 0.2 \\
Producing bottom hole pressure, psi & 1000 \\
Total injection, PV & 1.2 \\
\hline
\end{tabular}

pressure. For DME injection, the first-contact miscibility occurs under the reservoir conditions. The first-contact miscibility had occurred because the interfacial tension (IFT) was continuously zero during production. In contrast, the minimum IFT was about 5 dyne/cm during multiple contacts between $\mathrm{CO}_{2}$ and reservoir oil (Fig. 3). Figure 4 indicates that the oil viscosity during DEW was lower than that during $\mathrm{CO}_{2}$ flooding throughout the reservoir. The oil viscosity was more highly reduced by $\mathrm{CO}_{2}$ near the injector, to $0.9 \mathrm{cP}$. The reduction was much more effective using DME with a minimum value of $0.1 \mathrm{cP}$, and the amount was comparable to the effect with LPG because they both have similar characteristics except water solubility. In the middle of the reservoir, the oil viscosity decreased to $0.87 \mathrm{cP}$ with multiple contact between oil and continuous injected $\mathrm{CO}_{2}$, in contrast, it did get to $0.55 \mathrm{cP}$

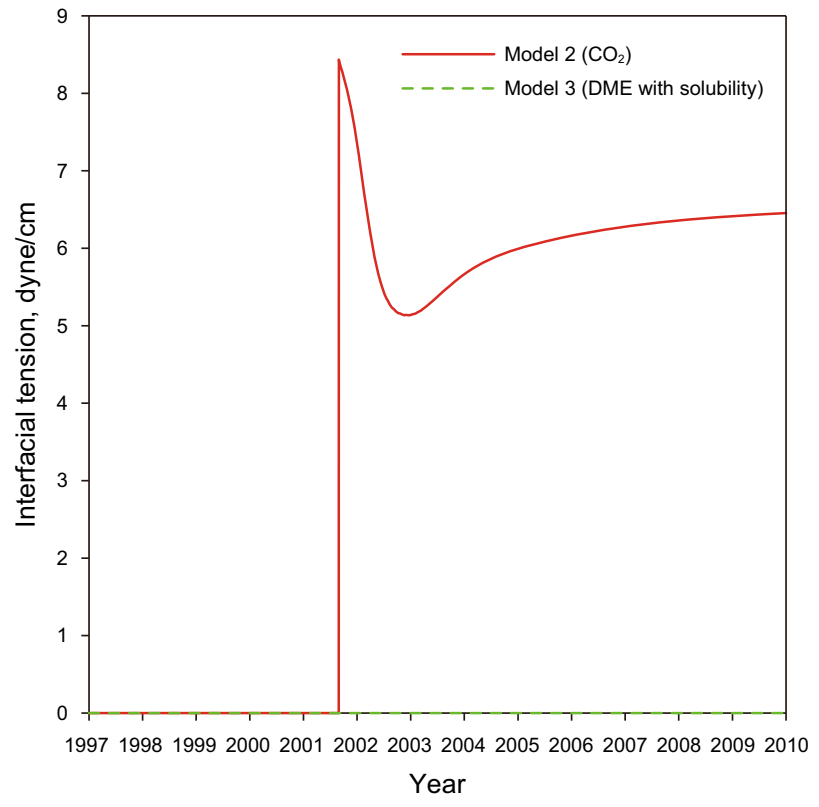

Fig. 3 Interfacial tension between injected fluid and reservoir oil at the middle of the reservoir

with DME. For continuous $\mathrm{CO}_{2}$ injection, the oil viscosity reduced to $0.9 \mathrm{cP}$ near the producer, and it was less effective than with DME, which reduced to $0.7 \mathrm{cP}$. Although LPG had a similar effect to DME near the injector, it had less effect because it could not be carried to reach the producer. The oil swelling effect followed the same trend as the viscosity reduction. DME caused oil swelling, resulting in an oil volume increment, such that the oil density reduction was much greater than that of $\mathrm{CO}_{2}$ 

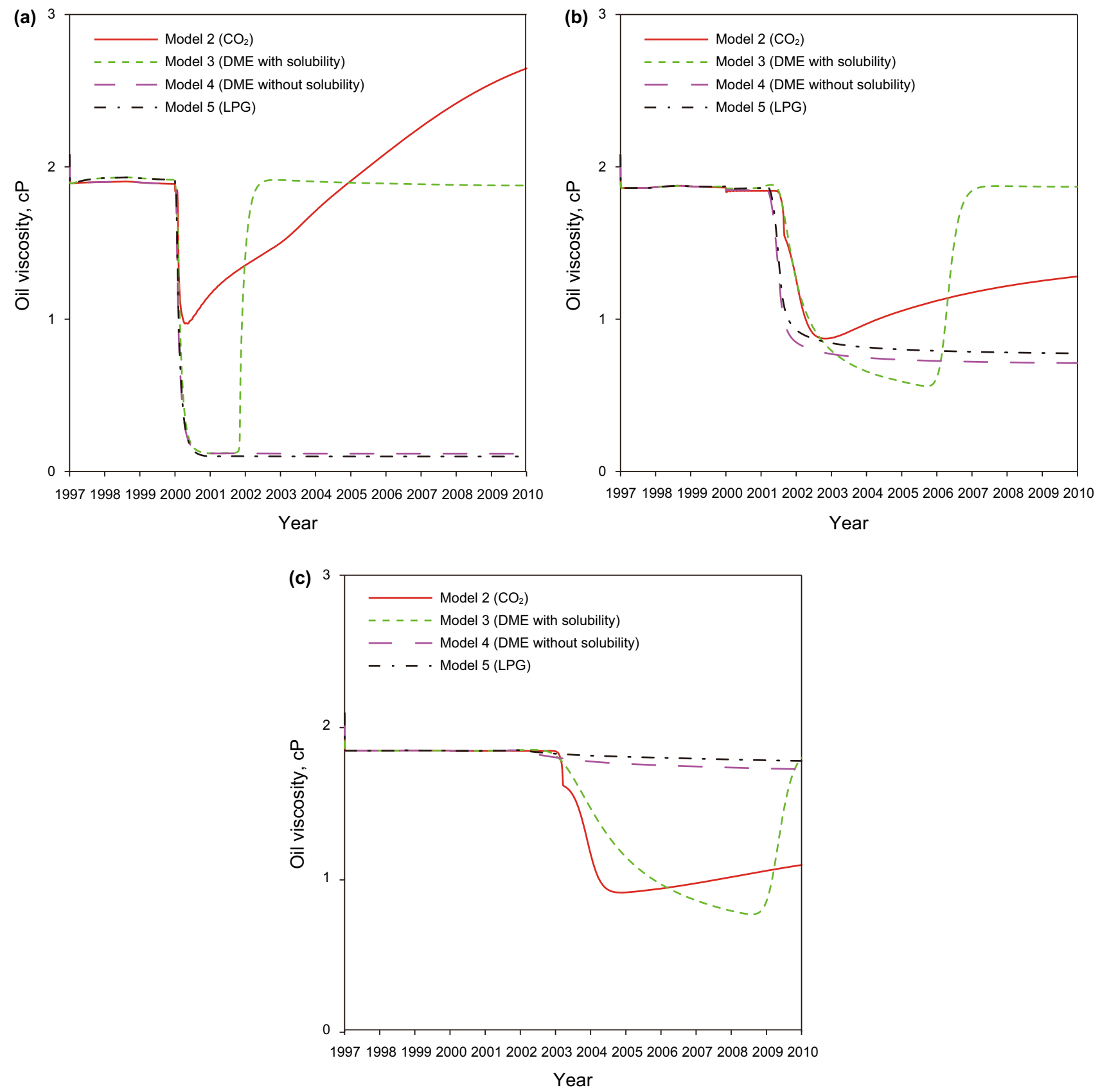

Fig. 4 Oil viscosity of Models 2-5 near the injector (a), at the middle of the reservoir (b), and near the producer (c)

injection (Fig. 5). At a density of $50.9 \mathrm{lb} / \mathrm{ft}^{3}$ for original oil, the minimum oil density was $49.9 \mathrm{lb} / \mathrm{ft}^{3}$ for $\mathrm{CO}_{2}$ flood and $46.1 \mathrm{lb} / \mathrm{ft}^{3}$ for DME injection.

\subsection{Water solubility effect}

DME remaining in residual oil after DME injection was recovered by chase water because of its solubility in the aqueous phase. After all of the DME was extracted by freshwater injection, the components of residual oil returned to the initial state, as the oil viscosity and density reverted to the initial values. In contrast, $\mathrm{CO}_{2}$ can dissolve only in light to intermediate components, resulting in higher viscosity and density of residual oil than the initial values (Figs. 4, 5). Fresh chase water became saturated by DME and contacted oil that was not saturated with DME from the initial injection. The chase water acted as a DME carrier to reduce the oil viscosity to a greater extent than those of Models 4 and 5 near the producer because LPG does not dissolve in water (Fig. 4). Figure 6 shows the mole fraction of DME in the oil phase near the injector and producer. In results of Model 4, DME dissolved to a much 


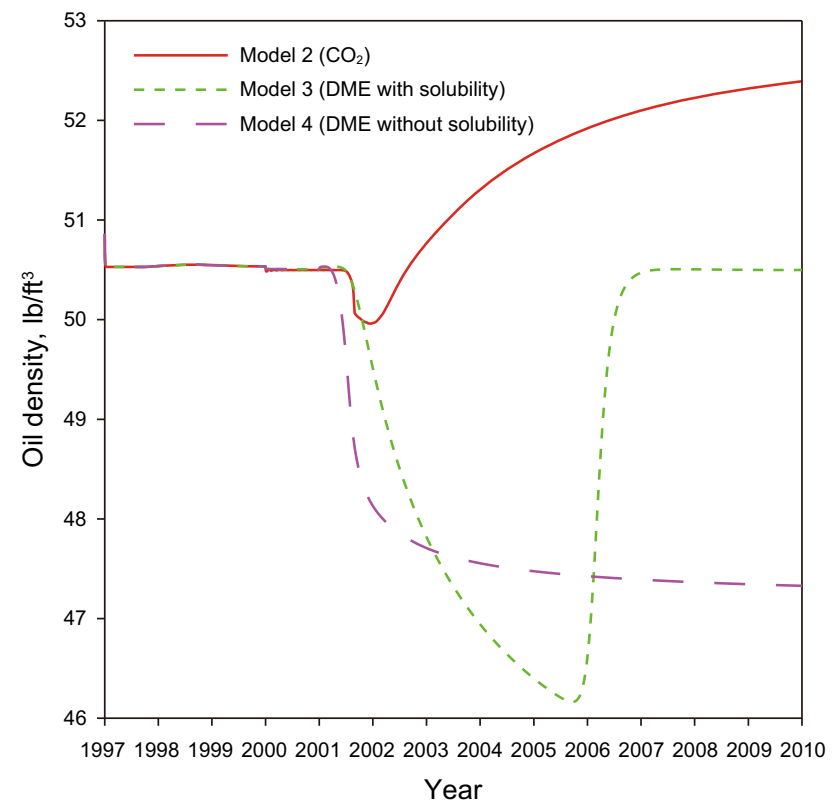

Fig. 5 Oil density of Models 2-4 at the middle of the reservoir

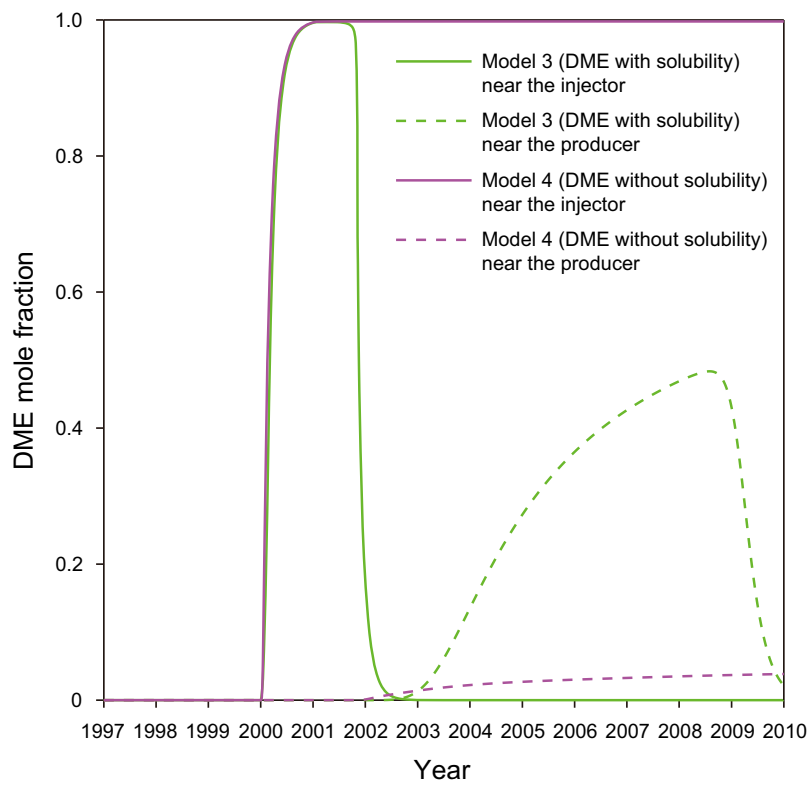

Fig. 6 DME mole fraction in the oil phase near the injector and producer

greater extent near the injector than near the producer because it did not reach the producer in sufficient quantity. However, the mole fraction of DME in the oil phase near the injector was reduced to zero by chase water; as it was carried to the producer, an increase in DME mole fraction near the producer occurred in the solubility case of Model 3. The increased DME concentration near the producer started to decrease due to continuous contact with freshwater, which reflects the production of DME accompanied by chase water.

\subsection{Oil recovery}

Results of oil recovery with various flooding models are compared in Fig. 7. The oil recovery from Models 1 and 2 was $59 \%$ and $68 \%$, respectively, and the recovery with Model 4 was 75, which is 27\% higher than that of Model 1. Considering the water solubility effect, the recovery of Model 3 increased by $5 \%$ over Model 4 to $79 \%$, which is $34 \%$ higher than that of conventional waterflood. At the first stage of DME injection, because of DME solubility in connate water, the oil recovery with Model 3 was lower than that of Model 4 from 2002 to 2004. The oil recovery of Model 3 became higher from 2004 due to oil mobility improvement near the producer. Model 5, with LPG injection instead of DME, followed a similar trend to Model 4 because LPG solubility in water is almost zero.

\section{Conclusions}

DME injection leads to oil viscosity reduction and oil swelling, resulting in improved oil mobility. A compositional simulation model has been developed to forecast the performance and to determine transport mechanisms with water-soluble DME during the DEW process. DME remaining near the injector after injection was extracted by chase water, which acted as a DME carrier to improve oil mobility near the producer. For the model considering water-soluble DME (Model 3), the oil viscosity near the injector was reduced to $0.75 \mathrm{cP}$, which is $56 \%$ lower than results from the model not considering water solubility (Model 4). Higher oil recovery up to $79 \%$ was obtained

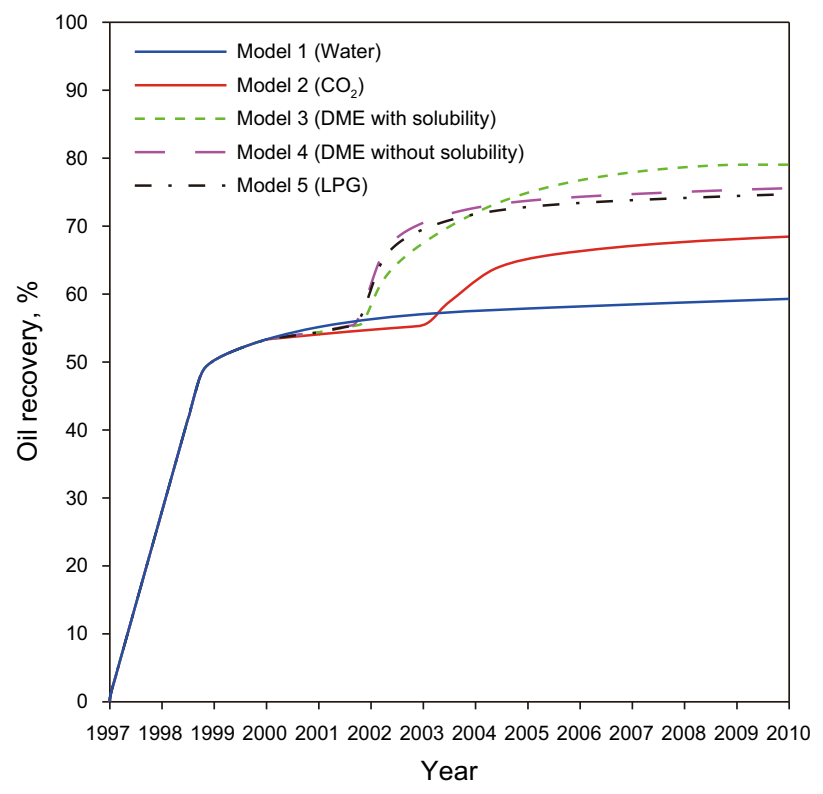

Fig. 7 Results of oil recovery with various injection scenarios 
from the water-soluble DME model compared with the model without water solubility, suggesting that the compositional model without consideration of water-soluble DME could underestimate performance of the DEW process. The developed model was shown to be useful in simulations of transport mechanisms of DEW, which were totally different from conventional water and $\mathrm{CO}_{2}$ flooding.

Acknowledgements This work was supported by the Energy Efficiency \& Resources Core Technology Program of the Korea Institute of Energy Technology Evaluation and Planning (KETEP) of the Ministry of Trade, Industry, \& Energy, Republic of Korea (No. 20152520100760).

Open Access This article is distributed under the terms of the Creative Commons Attribution 4.0 International License (http://crea tivecommons.org/licenses/by/4.0/), which permits unrestricted use, distribution, and reproduction in any medium, provided you give appropriate credit to the original author(s) and the source, provide a link to the Creative Commons license, and indicate if changes were made.

\section{References}

Chernetsky A, Masalmeh S, Eikmans D, Boerrigter PM, Fadili A, Parsons $\mathrm{CA}$ et al. A novel enhanced oil recovery technique: experimental results and modelling workflow of the DME enhanced waterflood technology. In: Abu Dhabi International Petroleum Exhibition and Conference, Abu Dhabi, UAE, November 9-12, 2015. https://doi.org/10.2118/177919-MS.

Fassihi MR, Gillham TH. The use of air injection to improve the double displacement processes. In: SPE Annual Technical Conference and Exhibition, Houston, Texas, October 3-6, 1993. https://doi.org/10.2118/26374-MS.

Fazelipour W. Predicting asphaltene precipitation in oilfields via the technology of compositional reservoir simulation. In: SPE International Symposium on Oilfield Chemistry, Texas, April 11-3, 2011. https://doi.org/10.2118/141148-MS.

Ganjdanesh R, Rezaveisi M, Pope GA, Sepehrnoori K. Treatment of condensate and water blocks in hydraulic-fractured shalegas/condensate reservoirs. SPE J. 2016;21(2):1-10. https://doi. org/10.2118/175145-PA.

Gatlin C, Slobod RL. The alcohol slug process for increasing oil recovery. J Pet Technol. 1960;12(3):84. https://doi.org/10.2118/ 1364-G.
Groot JA WM, Chernetsky A, te Riele PM, Dindoruk B, Cui J, Wilson LC et al. Representation of phase behavior and PVT workflow for DME enhanced water-flooding. In: SPE EOR Conference at Oil and Gas West Asia, Muscat, Oman, March 21-3, 2016. https://doi.org/10.2118/179771-MS.

Hu W, Wang Z, Ding J, Wang Z, Ma Q, Gao Y. A new integrative evaluation method for candidate reservoirs of hydrocarbon gas drive. Geosyst Eng J. 2015;18(1):8-44. https://doi.org/10.1080/ 12269328.2014.988299.

Japan DME Forum. DME Handbook. Japan: Japan DME Association; 2007. pp. 1-605.

Li YK, Nghiem LX. Phase equilibria of oil, gas and water/brine mixtures from a cubic equation of state and Henry's law. Can J Chem Eng. 1986;64(3):486-96. https://doi.org/10.1002/cjce. 5450640319.

Nelson Jr RD, Lide Jr DR, Maryott AA. Selected values of electric dipole moments for molecules in the gas phase. No. NSRDSNBS-10. National Standard Reference Data System, 1967, 1-49.

Parsons C, Chernetsky A, Eikmans D, te Riele P, Boersma D, Sersic I et al. Introducing a novel enhanced oil recovery technology. In: SPE Improved Oil Recovery Conference, Tulsa, Oklahoma, April 11-3, 2016. https://doi.org/10.2118/179560-MS.

Pedersen KS, Fredenslund A. An improved corresponding states model for the prediction of oil and gas viscosities and thermal conductivities. Chem Eng Sci. 1987;42(1):182-6. https://doi.org/ 10.1016/0009-2509(87)80225-7.

Peng DY, Robinson DB. A new two-constant equation of state. Ind Eng Chem Fundam. 1976;15(1):59-64.

Reid RC, Prausnitz JM, Sherwood TK. The properties of gases and liquids, 3rd edition, McGraw-Hill, 1977, 614.

Robinson DB, Peng DY. The characterization of the heptanes and heavier fractions, Research Report 28. Tulsa: Gas Processors Association; 1978. p. 36.

Sander R. Compilation of Henry's law constants (version 4.0) for water as solvent. Atmos Chem Phys. 2015;15(8):4399-981. https://doi.org/10.5194/acp-15-4399-2015.

Srivastava RK, Huang SS, Dong M. Laboratory investigation of Weyburn $\mathrm{CO}_{2}$ miscible flooding. $\mathrm{J}$ Can Pet Technol. 2000;39(2):41-51. https://doi.org/10.2118/00-02-04.

Taber JJ, Kamath ISK, Reed RL. Mechanism of alcohol displacement of oil from porous media. SPE J. 1961;1(3):19-212. https://doi. org/10.2118/1536-G.

Talbi K, Kaiser TMV, Maini BB. Experimental investigation of $\mathrm{CO}_{2-}$ based VAPEX for recovery of heavy oils and bitumen. J Can Pet Technol. 2008;47(4):1-8. https://doi.org/10.2118/08-04-29. 